\title{
MULHERES NO TOPO: AS CONTADORAS PARANAENSES ESTÃO ROMPENDO O GLASS CEILING?'
}

\author{
Franciele Machado de Souza ${ }^{2}$ \\ Simone Bernardes Voese ${ }^{3}$ \\ Katia Abbas ${ }^{4}$
}

\begin{abstract}
Resumo: Ao longo das últimas décadas um número crescente de mulheres tem se formado em Ciências Contábeis no Brasil. No entanto, a sub-representação das mulheres na Contabilidade simplesmente evoluiu da segregação horizontal, rejeição das mulheres da profissão, para uma segregação vertical, em que as mulheres encontram dificuldades de alcançar altos cargos gerenciais dentro das organizações (DAMBRIN; LAMBERT, 2008). No entanto, Altman e Simpson (2000) sugerem que essas barreiras podem ser perfuradas por mulheres mais jovens. Neste sentido, questiona-se: As mulheres contadoras mais jovens estão rompendo o glass ceiling na busca pela progressão na carreira contábil? A fim de explorar esta proposição, uma análise comparativa entre as mulheres contadoras "jovens" e "maduras" foi realizada. As informações foram coletadas, com auxílio da plataforma Google Docs, a partir de um questionário construído com base nas pesquisas de Gammie et al. (2007). A amostra final resultou em 63 respondentes formadas em duas instituições de ensino superior (IES) do estado do Paraná. Os resultados indicam que a atuação da mulher contabilista está se restringido em níveis hierárquicos mais baixos das organizações. Verificou-se, também, que as mulheres contadoras ainda estão enfrentando o glass ceiling na busca de progressão em seu trabalho. Conclui-se que, apesar do movimento em direção a uma maior igualdade de direitos na sociedade em termos de responsabilidades domésticas e familiares e a maior possibilidade de escolha das mulheres, seu progresso profissional ainda tem sido limitado. Os resultados desta pesquisa podem ser um ponto de partida para o desenvolvimento de novos estudos que tenham como objetivo a análise da desigualdade de gênero na profissão contábil no Brasil, que é ainda escassa, além de incentivar atitudes próativas das empresas na elaboração de práticas de trabalho flexíveis para as mulheres contadoras.
\end{abstract}

Palavras-chave: Mulheres contadoras. Glass ceiling. Work-life balance.

Artigo apresentado no $4^{\circ}$ Fast Track ANPCONT no dia 18/08/2014

E-mail: m.franciele@gmail.com. Universidade Federal do Paraná - UFPR

${ }^{3}$ E-mail: simone.voese@gmail.com. Universidade Federal do Paraná - UFPR

${ }^{4}$ E-mail: kabbas@uem.br. Universidade Estadual de Maringá - UEM

- DOI: http://dx.doi.org/10.14392/asaa.2015080206

- Artigo sumetido em: 22/09/2014. Revisőes requeridas: 19/12/2014. Revisões requeridas em: 11/04/2015. Aprovado em: 16/08/2015. 


\title{
WOMEN ON TOP: THE COUNTERS PARANENSES ARE BREAKING
} THE GLASS CEILING?

\begin{abstract}
Throughout the latter decades an increasing number of women has graduated in Accounting in Brazil. However, their under representation in the activity simply evolved from horizontal segregation, women rejection over the occupation, to a vertical segregation, where the women find difficulties to reach higher management positions inside the companies (DAMBRIN; LAMBERT, 2008). But Altman and Simpson (2000) suggest that these barriers can be broken by younger women. In this sense, a question arises: Are the younger female accountants breaking down the glass ceiling in the pursuit of career progression in Accounting? Intending to explore this proposition, a comparative analysis among young and aged female accountants was made. Information was collected through Google Docs tool, from a questionnaire based on Gammie et al. (2007) research. The final sample resulted in 63 respondents graduated in two College Education Institutions in the state of Paraná. The results indicate that the performance of female accountants is strict to lower hierarchical levels in the organizations. It was also noticed that the female accountants are still facing the glass ceiling in the pursuit of job progression. In conclusion, despite the movement towards a bigger equality of rights within the society in terms of household and family responsibilities and a bigger possibility of choice for women, their career progress is still limited to job positions. The results of this research can be a bottom line for the development of new studies that have the aim to analyze the gender inequality in accounting occupation in Brazil, which is scanty, and also motivate pro-active attitudes of the companies in formulating flexible job routines for female accountants.
\end{abstract}

Keywords: Women Accountants. Glass Ceiling. Work-life balance. 


\section{INTRODUÇÃO}

Historicamente as mulheres foram excluídas dos cargos gerenciais da profissão contábil (Kirkham, 1992; Roberts \& Coutts, 1992) sendo atribuídas a elas funções de secretária ou serviços gerais (Mckeen \& Richardson, 1998) por serem consideradas intelectualmente incapazes para exercer um papel de gestão (Lehman, 1992). Portanto, esta exclusão intelectual e moral representou um desafio para as mulheres participarem cada vez mais da educação e, posteriormente, até alcançar o papel gerencial exercido pelos homens nas empresas (Broadbent \& Kirkham, 2008).

Ao longo das últimas décadas um número crescente de mulheres tem se formado em Ciências Contábeis e vêm conquistando os espaços sociais, profissionais, culturais e políticos. A participação feminina na força de trabalho tem crescido (Lameiras, 2013) e as pressões por inclusão e justiça são cada vez mais fortes. Desse modo, elas estão mudando a cultura corporativa, desafiando estereótipos e trabalhando em ambientes tradicionalmente dominados pelos homens (Gammie et al., 2007).

Adicionalmente, as relações familiares vêm sofrendo mudanças, de modo que a estrutura familiar ancorada na presença de um chefe masculino vem perdendo força. Segundo dados da Pesquisa Nacional de Amostra por Domicílio (PNAD), a proporção de mulheres chefes de família no Brasil saltou de 27\%, em 2001, para 36\%, em 2012 (Lameiras, 2013). Segundo dados do Instituto de Pesquisa Econômica Aplicada (IPEA) a participação feminina na população economicamente ativa (PEA) no Brasil, entre 1950 e 2010, aumentou de 13,6\% para 48,9\% (Lameiras, 2013), portanto mais de 35 pontos percentuais em um período de 60 anos.

Este expressivo aumento é reflexo de uma série de alterações na sociedade, que passou a reconhecer não só os direitos das mulheres mas, também, a sua capacidade intelectual (Lameiras, 2013). No contexto do Conselho Federal de Contabilidade (CFC) no Brasil a percentagem de contadores do sexo feminino aumentou de $37 \%$ para $44 \%$ no período de 2004-2011. Estas últimas ideias formam o núcleo do conceito de critical mass, desenvolvida por Kanter (1977a; 1977b) e Dahlerup(1988), que, respectivamente, analisaram as experiências de mulheres que formam pequenas minorias nas esferas corporativas e políticas. Childs e Krook (2008) relatam que a critical mass theory procura explicar situações em que o aumento do número de mulheres resulta em uma maior atenção as suas necessidades. Dessa forma, o acréscimo da representação numérica das mulheres na contabilidade é um passo crucial para a sua progressão hierárquica dentro das organizações (French \& Meredith, 1994).

Por outro lado, a sub-representação das mulheres simplesmente evoluiu da segregação horizontal, significando a rejeição das mulheres da profissão, para uma segregação vertical, em que as mulheres encontram dificuldades de alcançar altos cargos gerenciais dentro das organizações (Dambrin \& Lambert, 2008). Verifica-se que a dificuldade de ascensão profissional das mulheres contadoras consiste no fenômeno conhecido como glass ceiling, entendido como uma barreira sutil, invisível, mas forte, quase intransponível, que dificulta a promoção das mulheres aos níveis superiores nas organizações (Morrison \& Glinow, 1990).

Gammie et al. (2007) analisaram em que medida o glass ceiling continua a ser um fenômeno do século 21 para as mulheres contadoras escocesas. Os autores relatam que as mulheres contadoras escocesas ainda estão enfrentando o glass ceiling na busca da progressão de sua carreira profissional, pois as empresas de Contabilidade continuam a adotar uma cultura machista, principalmente em 
relação ao regime de trabalho. Cabe ressaltar que, em relação as pesquisas com mulheres contadoras, o presente estudo segue na mesma linha do trabalho de Gammie et al. (2007), se diferenciando do mesmo em termos temporais e metodológicos, já que o presente estudo não analisa a progressão das mulheres contadoras a nível de parceria.

Ainda segundo Gammie et al. (2007), a cultura machista está associada com a profissão contábil pela necessidade percebida de se trabalhar por longas horas (Monks \& Barker, 1996; Mckeen \& Bujaki, 1998); exigência de obter e manter clientes (Crompton, 1987; Hanlon, 1994; Sikka Wilmott, 1995; HanIon, 1996; Monks \& Barker, 1996); capacidade para demonstrar flexibilidade e mobilidade (Altman \& Simpson, 2000) e pelo networking ser orientado e dominado pelos homens (Okanlawon, 1994; Barker \& Monks, 1998; Linehan et al., 2001).

Ramdhony, Oogarah-Hanuman e Somir (2013) pesquisaram a progressão na carreira de mulheres contadoras nas Ilhas Maurício. Os resultados encontrados revelam que, embora houve um aumento significativo no número de mulheres contadoras, elas não têm alcançado altos cargos gerenciais. Foram constatados ainda que, não existe relação entre a idade e a posição ocupada e que as barreiras que estão impedindo o avanço das mulheres ao longo da carreira são principalmente o glass ceiling e os conflitos de work-life balance.

A literatura estrangeira não é tímida ao discutir a desigualdade de gênero na profissão contábil. No entanto, Ramdhony, Oogarah-Hanuman e Somir (2013) comentam que a maioria das pesquisas nesta área encontram-se no Reino Unido, EUA e Austrália, onde os profissionais contábeis estão bem consolidados e os movimentos feministas estabelecidos. Contudo, no Brasil ainda são raros os estudos sobre essa temática.

No contexto brasileiro, Cappellin (2008) pesquisou as posições ocupadas pelas mulheres em alta hierarquia das profissões (diretoras e gerentes) nas empresas brasileiras, entre 1996 a 2005. Concluiu que as mulheres têm alcançado o diploma universitário e ampliado sua presença na economia e na sociedade. Mas estas mudanças não incluem um expressivo aumento de sua integração em funções de tomada de decisão.

Pires et al. (2010) investigaram as práticas adotadas pelas empresas brasileiras para o atendimento a saúde, atração e retenção das mulheres em seu quadro funcional. Constataram que as organizações têm desenvolvido de maneira lenta suas ações voltadas para as mulheres, mesmo aquelas empresas que se destacam como as melhores para se trabalhar no Brasil apresentam diferentes compreensões e esforços quanto às práticas voltadas para as mulheres.

Especificamente na profissão Contábil, Altoé (2014) pesquisou os fatores explicativos do work-life balance para contadores paranaenses. Concluiu que, os contadores que apresentam uma jornada excessiva de trabalho acreditam que esta dedicação reflete negativamente nas demais esferas e consequentemente impacta na sua percepção de work-life balance. Além disso, a autora relata que os cargos de atuação das mulheres contadoras no Paraná são de auxiliar contábil, assistente contábil e analista contábil. Deste modo, a autora constatou que quanto mais baixo o nível hierárquico maior é a atuação da mulher na contabilidade. 
Apesar do fato de a Contabilidade já não ser uma profissão dominada exclusivamente por homens, a discrepância de gênero em nível de gerência ainda é evidente (Gammie et al., 2007). Por outro lado, Altman e Simpson (2000) sugerem que o glass ceiling pode ser perfurado por mulheres mais jovens. Dessa forma, esta pesquisa se propõe responder à seguinte questão: As mulheres contadoras "mais jovens" estão rompendo o glass ceiling na busca pela progressão na carreira contábil?

Este estudo justifica-se pelo fato de que cada vez mais mulheres entram no mercado de trabalho e sua dificuldade em atingir os cargos gerenciais tornou-se motivo de pesquisa e debate (Lineham \& Walsh, 1999). No entanto, não foram encontradas na literatura nacional pesquisas que abordassem especificamente este tema, o que avaliza a contribuição singular desta pesquisa para o entendimento do fenômeno da desigualdade de gênero no ambiente contábil.

Outra motivação para a presente pesquisa foi a constatação de indícios de que algumas organizações têm reconhecido a necessidade de adoção de iniciativas que incentivem as mulheres a permanecer e se desenvolver nessas empresas (Gammie et al., 2007). Consequentemente, seria de se esperar que a retenção, desenvolvimento e progressão das mulheres no local de trabalho se torne prioridade para as empresas de Contabilidade modernas (Gammie et al., 2007).

\section{FUNDAMENTAÇÃO TEÓRICA}

Segundo Scott (1986), gênero é considerado um elemento constitutivo de relações sociais baseado nas diferenças percebidas entre os sexos, e a primeira forma de significar as relações de poder. A diferenciação entre gêneros é uma maneira estereotipada de distinguir as limitações e as capacidades entre homens e mulheres baseados em características sexuais e gender roles (Luca et al., 2011). Bell Hooks (2014) menciona que sexismo entre homens e mulheres é mais frequentemente expresso na forma da dominação masculina, que leva à discriminação, exploração ou opressão. Entre as mulheres, os valores da supremacia do sexo masculino são expressoos através de um comportamento suspeito, defensivo, competitivo. Para a autora, o sexismo leva as mulheres a desvalorizar o trabalho de cuidadora do lar, e inflar o valor do emprego e carreira.

Diversas pesquisas discutem a desigualdade de gênero na carreira da mulher contabilista (Maupin, 1993; Gammie \& Gammie, 1995; Whiting \& Wright, 2001; Devonport, 2007; Gammie et al., 2007) e estas discussões estão baseadas fundamentalmente em três teorias (Morrison \& Von Glinow, 1990), a saber: centrada na estrutura (estrutura); centrada na pessoa (atributos) e a centrada no preconceito (atitudes). As dificuldades na progressão da carreira feminina parecem ser uma consequência da relação complexa entre essas abordagens (Gammie et al., 2007). Desta forma, estas teorias serão utilizadas para estruturar a revisão da literatura e os resultados desta pesquisa.

A teoria centrada na estrutura assume que a causa da desigualdade de gênero são as políticas e práticas do sistema social, que possui uma estrutura dominada por homens (Devonport, 2007). Embora homens e mulheres sempre tenham atuado lado a lado na sociedade, a divisão no ambiente de trabaIho ainda é predominante (Walby, 1988). Por outro lado, as mulheres muitas vezes se concentram em aspectos da sociedade menos visíveis e menos valorizados, enquanto os homens focam sua atenção em aspectos que são publicamente valorizados (Risman \& Johnson-Sumerford, 1998).

Tradicionalmente, as mulheres eram vistas como inferiores no ambiente de trabalho, independente de quão árduo era seu trabalho ou de quanto elas provavam ser capazes (Gammie et al., 2007). Entretanto, quanto mais as mulheres progrediram e se prepararam para atuar nos altos níveis, a segregação 
deveria ter se tornado menos predominante. Contudo, se as organizações mantiverem sua estrutura patriarcal, na qual o poder é concedido aos homens, talvez a habilidade das mulheres para alcançar o topo seja abreviada (Hultin \& Szulkin, 1999).

Já a teoria centrada na pessoa (atributos) sugere que existem diferenças de comportamento entre homens e mulheres e que isso justifica o seu tratamento diferenciado (Gammie et al., 2007). No tocante as diferenças biológicas, Bryson (1992) argumenta que os homens são competidores natos e agressivos, enquanto a capacidade biológica das mulheres de dar à luz significa que elas possuem "virtudes femininas" de paz, cuidado e cooperação.

A composição genética dos homens exerce influência na progressão profissional no mercado de trabalho, as mulheres foram consideradas menos ambiciosas e menos orientadas para a carreira do que os homens (Schwartz, 1989; Lamsa \& Sintonen, 2001). Esse tipo de comportamento foi constatado por Judson (1997), em que as mulheres demonstram maior comprometimento em equilibrar a carreira e sua vida pessoal e que os homens estavam satisfeitos em colocar a carreira acima da família. No entanto, segundo Mead (1971) o comportamento dos indivíduos depende de um aprendizado, de um processo chamado de endoculturação. Para a autora, um menino e uma menina agem de forma diferente não em função de seus hormônios, mas em decorrência de uma educação diferenciada.

$\mathrm{Na}$ teoria centrada no preconceito (atitudes) a discriminação pelo grupo dominante é a principal causa das desigualdades (Morrison \& Von Glinow, 1990). Diversas pesquisas apontam que ainda existe preconceito na profissão contábil (Ciancanelli et al., 1990; Maupin, 1993; Barker \& Monks, 1998), em termos de estereótipos ou experiências. Um estereótipo é uma forte representação social que impede uma escolha ajustada à realidade, quando se trata de profissões (Bellodi, 2006). Acredita-se que os estereótipos contribuem para a falta de oportunidades no desenvolvimento de carreira para as mulheres (Hymowitz \& Schellhardt, 1986).

Um desses estereótipos é a percepção de que as mulheres não voltam para a profissão contábil depois de ter filhos. No entanto, estudos apontam uma elevada percentagem de mulheres que retornaram ao trabalho depois de terem filhos (Hooks \& Cheramy, 1994; Almer \& Single, 2007). Há também uma percepção de que as mulheres que têm filhos não estão comprometidas com a organização (Maupin, 1993; Gammie \& Gammie, 1995; Windsor \& Auyeung, 2006) e que são menos dispostas a fazer as horas extras necessárias para obter uma promoção (Barker, Monks, 1998; Windsor \& Auyeung, 2006).

Embora essa teoria seja baseada na atitude de outras pessoas para com as mulheres, há uma justaposição considerável entre a teoria centrada na pessoa e a teoria centrada na estrutura (Gammie et al., 2007). As diferenças de gênero parecem ser a consequência de uma relação complexa entre fatores que surgem de teorias interligadas. As influências da estrutura, atributos e atitudes se combinam para criar o glass ceiling para as mulheres progredirem em sua carreira. A influência relativa de cada uma delas pode depender tanto da mulher contadora, quanto da organização que a emprega (Gammie et al., 2007).

Jackson (2001) destacou dois principais aspectos do glass ceiling, as barreiras de comportamento e as contextuais. As barreiras de comportamento são as atitudes dos homens em relação às mulheres, tais como estereótipos, preconceitos e o reconhecimento de que as mulheres são uma ameaça ao avanço masculino. As barreiras contextuais são a forma tradicional do trabalho e a falta de modelos femininos (Gammie et al., 2007). Há evidências de que a complexidade da relação entre essas barreiras conspira para criar o glass ceiling e garantir a sua existência, conforme apresentado na Figura 1. 


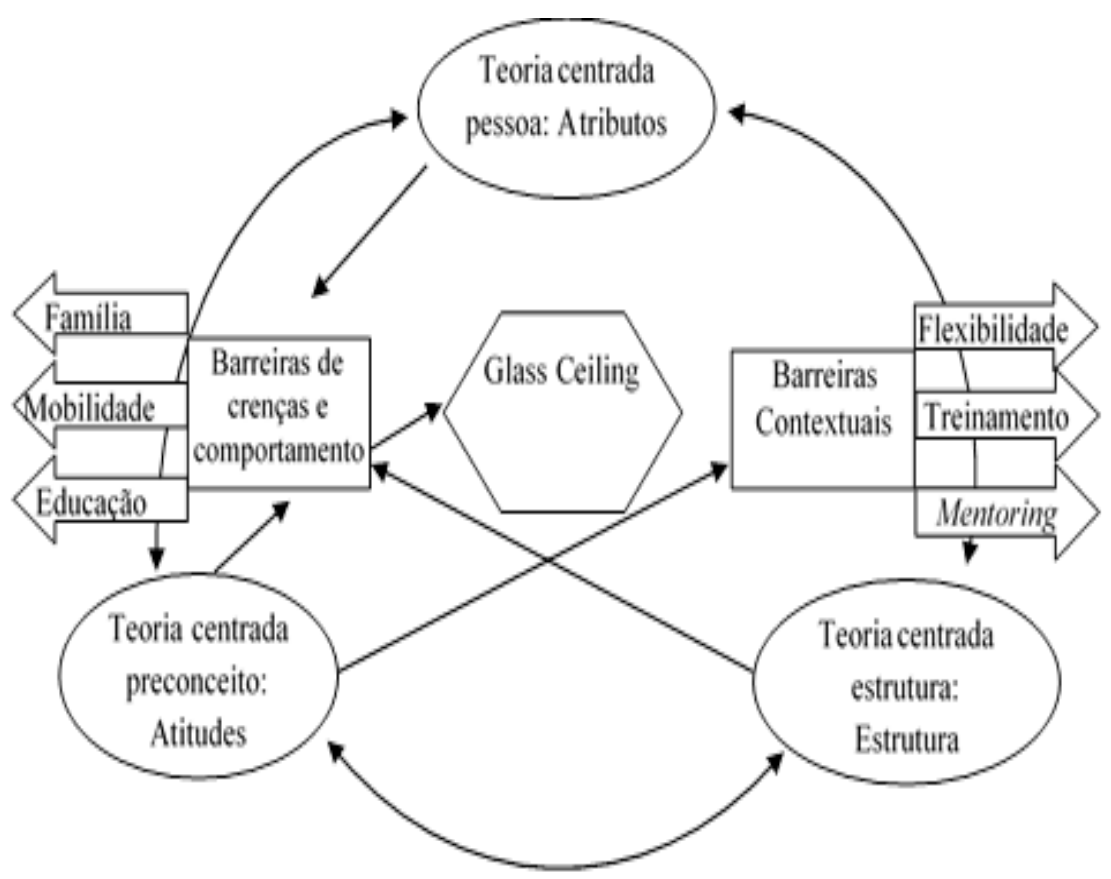

Figura 1: Influências Glass Ceiling Fonte: Adaptado de Gammie et al. (2007).

Altman e Simpson (2000) sugerem que essas barreiras podem ser perfuradas por mulheres "mais jovens". Neste sentido, Blätten-Mink, Kramer e Misschau (2000) relatam que as mulheres "mais jovens" têm atitudes e expectativas diferentes das "maduras", e que as mudanças na educação e na cultura da sociedade têm facilitado a compatibilidade dos compromissos de trabalho com os familiares. As mudanças que ocorreram estão dentro do ambiente familiar tradicional, educacional e o impacto resultante sobre a mobilidade, com uma ênfase reduzida no casamento e paternidade, e as responsabilidades parentais partilhadas têm o potencial de diminuir as barreiras atitudinais e contextuais (Gammie et al., 2007).

Ao longo da última década, a crescente conscientização sobre o glass ceiling incentivou a criação de políticas específicas para ajudar as mulheres na tentativa de romper essa barreira. O princípio fundamental das iniciativas de work-life balance é proporcionar um equilíbrio flexível entre o trabalho e os compromissos familiares dos funcionários. Este equilíbrio inclui questões sobre flexibilidade de horários de trabalho, licença maternidade e interrupções de carreira programadas (Gammie et al., 2007).

Considerando as diferenças geracionais em work-life balance, Conger (1998) relata que a geração baby boomers (faixa etária de 50-65 anos) são os indivíduos que lutaram por seus direitos, buscam por estabilidade profissional e se adaptam com maior facilidade a um emprego. A geração X (faixa etária 36-49 anos), contempla as pessoas que valorizam o trabalho e aspiram por ascensão profissional (OLIVEIRA, 2009). Já os índividuos da geração Y (faixa etária 19-35 anos) prezam pelos aspectos pessoais e familiares em detrimento aos profissionais, e apresentam comprometimento organizacional à medida que recorrem a arranjos de trabalho flexíveis que favorecem de certa forma ao work-life balance (Catalyst, 2001). Por fim, quaisquer iniciativas nesta área têm o potencial de melhorar as condições de trabalho para ambos os sexos, especialmente aqueles que são pais e têm responsabilidades de assistência a família (Eoc, 1999). A implementação de tais iniciativas consiste no primeiro passo para o desenvolvimento de programas para recrutar, reter e desenvolver a carreira de mulheres contadoras (Gammie et al., 2007). O maior problema, segundo McKeen e Bujáki (1994) é que não é suficiente apenas introduzir 
estas iniciativas, a menos que a cultura dentro da organização seja alterada de modo que seja aceitável aderir a tais programas da empresa.

\section{METODOLOGIA DA PESQUISA}

A inspiração inicial para esta pesquisa foram o estudo de Gammie et al. (2007), intitulado "Women of ICAS Reaching the Top: The Demise of the Glass Ceiling" que trazia como objetivo avaliar em que medida o glass ceiling continua a ser um fenômeno do século 21 para as mulheres contadoras escocesas empregadas em empresas de Contabilidade, e a pesquisa de Ramdhony, Oogarah-Hanuman e Somir (2013), intitulada "Career Progression of Women in Accounting - The Case of Mauritius" que tinha como objetivo investigar a progressão na carreira de mulheres contabilistas nas Ilhas Maurício.

Esta pesquisa empírica tem natureza descritiva, pois tem como objetivo de responder a uma questão de pesquisa, bem como apontar detalhes de uma determinada situação e tem caráter predominantemente quantitativo (Cooper \& Schindler, 2003). A abordagem quantitativa caracterizou-se pelo uso de estatística descritiva e teste não-paramétrico. Para atingir o objetivo da pesquisa, será utilizada a hipótese sustentada por Gammie et al. (2007) e Altman e Simpson (2000).

- H1: As mulheres contadoras mais"jovens" estão rompendo o glass ceiling na busca pela progressão na carreira contábil.

Pressupõe-se inicialmente, que as mudanças na oferta educativa e na estrutura tradicional familiar tiveram impacto sobre as mulheres "jovens" (Gammie et al., 2007).

O questionário utilizado foi adaptado da pesquisa de Gammie et al. (2007). Gammie et al. (2007) dividiu o questionário em cinco seções (perfil das entrevistadas, cultura social, cultura organizacional, porque as mulheres deixam de trabalhar em escritórios de contabilidade e as razões para aqueles muIheres criarem seu próprio negócio ou não estarem trabalhando atualmente). A pesquisa de Gammie et al. (2007 não disponibilizou os questionários no texto, mas foi possível a identificação das questões através da análise dos resultados apresentados nas pesquisas. Os resultados foram traduzidos por uma especialista.

Assim, o questionário foi estruturado em seis seções: a) seção A: contém questões relacionadas ao perfil das entrevistadas (18 itens); b) seção B: inclui questões sobre a cultura social que estas mulheres estão inseridas (7 questões objetivas e 1 questão em escala tipo likert); c) seção C: contém questões sobre a cultura organizacional das empresas (6 perguntas em escala tipo likert); d) seção D: visa verificar os fatores que atraem as mulheres para a profissão contábil (1 questão em escala tipo likert); e) seção E: visa identificar porque as mulheres deixam de trabalhar em Empresas de Serviços Contábeis (1 questão em escala tipo likert); f) seção F: busca entender as razões para as mulheres criarem seu próprio negócio (1 questão em escala tipo likert).

A relação da percepção de justiça na avaliação de desempenho e a folga organizacional foram mensuradas utilizando-se das variáveis expostas no constructo da pesquisa, conforme elucidado na Figura 2. 


\begin{tabular}{|c|c|c|}
\hline VARIÁVEIS E AUTORES & MENSURAÇÃO & EXEMPLOS DE ASSERTIVAS \\
\hline $\begin{array}{l}\text { Questões demográficas } \\
\text { (Gammie et al., 2007) }\end{array}$ & $\begin{array}{c}\text { Foram expostas } 18 \text { assertivas mul- } \\
\text { tipla escolha. }\end{array}$ & $\begin{array}{c}\text { Informações sobre idade, sexo, } \\
\text { estado civel, número de filhos, } \\
\text { etc. }\end{array}$ \\
\hline $\begin{array}{c}\text { Cultura social } \\
\text { (Gammie et al., 2007) }\end{array}$ & $\begin{array}{c}\text { Foram expostas } 7 \text { assertivas em es- } \\
\text { cala de } 1 \text { a } 5 \text {, sendo que } 5 \text { indica } \\
\text { concordo totalmente e } 1 \text { discordo } \\
\text { totalmente. }\end{array}$ & $\begin{array}{c}\text { Os cuidados infantis. A per- } \\
\text { cepção feminina sobre seu } \\
\text { trabalho. }\end{array}$ \\
\hline $\begin{array}{l}\text { Cultura organizacional } \\
\text { (Gammie et al., 2007) }\end{array}$ & $\begin{array}{c}\text { Foram expostas } 6 \text { assertivas em es- } \\
\text { cala de } 1 \text { a } 5 \text {, sendo que } 5 \text { indica } \\
\text { concordo totalmente e } 1 \text { discordo } \\
\text { totalmente. }\end{array}$ & $\begin{array}{c}\text { Requisitos para trabalhar por } \\
\text { longas horas. Percepções do } \\
\text { impacto por trabalhar meio- } \\
\text {-período. }\end{array}$ \\
\hline $\begin{array}{c}\text { Fatores que atraem as mulheres para } \\
\text { a profissão contábil } \\
\text { (Gammie et al., 2007) }\end{array}$ & $\begin{array}{l}\text { Foi exposta } 1 \text { assertiva em escala de } \\
1 \text { a } 5 \text {, sendo que } 5 \text { indica concordo } \\
\text { totalmente e } 1 \text { discordo totalmente. }\end{array}$ & $\begin{array}{c}\text { que influenciou sua escolha } \\
\text { pela profissão contábil }\end{array}$ \\
\hline $\begin{array}{l}\text { Porque as mulheres deixam de traba- } \\
\text { Ihar em escritórios de contabilidade } \\
\text { (Gammie et al., 2007) }\end{array}$ & $\begin{array}{l}\text { Foi exposta } 1 \text { assertiva em escala de } \\
1 \text { a } 5 \text {, sendo que } 5 \text { indica concordo } \\
\text { totalmente e } 1 \text { discordo totalmente. }\end{array}$ & $\begin{array}{l}\text { O que pode influenciar (ou } \\
\text { influenciou) sua saída de uma } \\
\text { empresa de contabilidade? }\end{array}$ \\
\hline $\begin{array}{c}\text { Porque as mulheres criam seu próprio } \\
\text { negócio (Gammie et al., 2007) }\end{array}$ & $\begin{array}{l}\text { Foi exposta } 1 \text { assertiva em escala de } \\
1 \text { a } 5 \text {, sendo que } 5 \text { indica concordo } \\
\text { totalmentee } 1 \text { discordo totalmente. }\end{array}$ & $\begin{array}{c}\text { Razões para a criação do pró- } \\
\text { prio negócio. }\end{array}$ \\
\hline
\end{tabular}

Figura 2: Constructo da pesquisa

Fonte: Elaborada pelas autoras.

A escala tipo likert utilizada foi de cinco pontos, que varia de concordo totalmente, até discordo totalmente. No entanto, os dados foram agrupados em três pontos (concordo, discordo e indiferente) para a análise das informações devido ao tamanho da amostra. As assertivas concordo totalmente e concordo foram agrupadas; as assertivas discordo e discordo totalmente também foram agrupadas para a análise dos resultados.

O pré-teste foi realizado com uma mulher contabilista formada há 18 anos, com vistas à implementação de eventuais adequações que viessem a contribuir para uma maior compreensão e agilidade no preenchimento. Todas as sugestões de melhorias foram analisadas e aceitas dentro do possível, para posterior aplicação do questionário.

A população pesquisada é composta por uma amostra retirada de mulheres formadas em Ciências Contábeis nos últimos sete anos de duas instituições de ensino superior (IES) públicas estaduais do Estado do Paraná, escolhidas pela conveniência das pesquisadoras. Este grupo de mulheres foi selecionado em função do tempo de sua formação acadêmica e que, potencialmente, pudessem já ter tido filhos, possibilitando condições para analisar a progressão na sua vida profissional e aspectos relacionados ao glass ceiling e work-life balance. A relação do total das mulheres formadas em Contabilidade foi fornecida por apenas uma das IES pesquisadas. Desta forma, não foi possível determinar a população total da pesquisa. Os convites para participar do estudo foram enviados por correio eletrônico para 
os endereços das participantes e mensagens inbox via Facebook utilizando o Google Docs como plataforma. O controle das mulheres participantes da pesquisa foi realizado pelo e-mail. $\mathrm{O}$ instrumento de pesquisa foi distribuído durante os meses de Janeiro a Março de 2014 na primeira IES, e de Maio a Julho de 2014 na segunda IES. A amostra final resultou em 63 respondentes, o que constituiu-se na amostra por acessibilidade. Neste tipo de amostra, o pesquisador apenas obtém os elementos a que tem acesso, admitindo que eles possam representar de forma adequada a população (Gil, 2008). No entanto, estes resultados não podem ser generalizados, restringem-se aos respondentes da pesquisa.

Embora o questionário tenha sido distribuído com base no ano de graduação (2005-2012), a análise foi realizada com base na idade, conforme realizado por Gammie et al. (2007) e Altman e Simpson (2000), que classificaram as mulheres em em "mais jovens" com idade menor ou igual a 29 anos, e"mais velhas" com trinta anos ou mais. Neste estudo, as mulheres foram classificadas em "jovens" com idade menor ou igual a 29 anos, e "maduras" com trinta anos ou mais, no momento da coleta de dados. As categorias foram selecionadas com base na lógica fornecida pelo IBGE que considera jovens as pessoas de 15 a 29 anos de idade, conforme o Estatuto da Juventude instituído pela Lei 12.852/2013 (IBGE, 2013). A escolha de dividir as mulheres desta forma justifica-se pelo fato da literatura sugerir que as mulheres “jovens" podem perfurar com sucesso o glass ceiling, devido às diferenças de atitude de suas colegas mais maduras (Altman \& Simpson, 2000). A distribuição das respostas está categorizada por idade, conforme Tabela 1.

Tabela 1-Distribuição da amostra classificadas por idade

\begin{tabular}{|c|c|c|}
\hline & Idade & Número de respondentes \\
\hline \multirow[t]{2}{*}{ Jovens } & $21-24$ & 20 \\
\hline & $25-29$ & 21 \\
\hline \multirow{3}{*}{ Maduras } & $30-34$ & 13 \\
\hline & $35-39$ & 6 \\
\hline & 40 ou mais & 3 \\
\hline \multicolumn{2}{|c|}{ Total } & 63 \\
\hline
\end{tabular}

Fonte: Elaborada pelas autoras.

Para o procedimento de análise dos dados, primeiramente se fez uso da estatística descritiva com o intuito de detalhar as características das mulheres contadoras que compõem a amostra. Posteriormente, análises com o objetivo de estabelecer as diferenças na progressão e percepções entre as mulheres "jovens" e "maduras" foram realizadas por meio do teste não-paramétrico de Pearson Chi-Square (Qui- Quadrado), conforme realizado por Gammie et al. (2007). O teste Qui-quadrado é uma medida padrão para examinar as diferenças estatísticas entre os dois grupos (Gammie et al, 2007). Cálculos e testes estatísticos foram desenvolvidos com o auxílio de software específico, adotando-se o nível de significância $(p)$ de $5 \%(a=0,05)$. 


\section{DESCRIÇÃO E ANÁLISE DOS RESULTADOS}

Os resultados obtidos com a pesquisa são apresentados a partir da discussão de cinco tópicos que compreendem: Questões demográficas, estrutura social, cultura organizacional das empresas, razões para as mulheres deixarem de trabalhar em Empresas de Serviços Contábeis e, finalmente, as razões para criarem seu próprio negócio. Os aspectos demográficos trazem para a discussão fatores que afetam diretamente as mulheres dentro da profissão contábil, tais como o estado civil, a maternidade e o status do trabalho atual. Em seguida, o impacto da estrutura da sociedade sobre as mulheres contadoras avalia a mudança da cultural em relação ao ambiente familiar, tais como a partilha das responsabilidades domésticas e familiares, licença maternidade e a interrupção na carreira. Posteriormente, verifica-se na estrutura social questões centradas na pessoa, tais como percepções, estereótipos e relacionamentos. Com relação a contribuição da cultura organizacional para o debate do glass ceiling, considera-se o ambiente de trabalho e as questões de work-life balance. Dessa forma, será explorado também porquê as mulheres deixam empresas de contabilidade, segundo a percepção das pesquisadas. E, igualmente, as razões para criarem seu próprio negócio. Essas percepções foram analisadas, considerando três categorias de mulheres: as que são empregadas em empresas de contabilidade, aquelas que trabalham fora do escritório contábil e as que não trabalham.

\subsection{As questões demográficas}

O estado civil da amostra das mulheres contadoras que se qualificaram entre 2005 e 2012, estão classificadas em termos totais e idade, conforme Tabela 2.

\begin{tabular}{|} 
Tabela 2: Estado civil da amostra \\
\begin{tabular}{|c|c|c|c|}
\hline Status & Total \% & Maduras & Jovens \\
\hline Solteira & 50,8 & 18,2 & 68,3 \\
Casada & 47,6 & 77,3 & 31,7 \\
Separada/Divorciada & 1,6 & 4,5 & 0,0 \\
\hline Total & 100 & 100 & 100 \\
\hline \multicolumn{2}{|c|}{ Teste Qui-quadrado $\left(\mathrm{X}^{2}\right)$} & 15,18 \\
\hline \multicolumn{2}{|c|}{ Nível de Significância $(\mathrm{p})$} \\
\hline
\end{tabular} \\
\hline
\end{tabular}

O estado civil das pesquisadas apresentou uma distribuição balanceada entre solteiras $(50,8 \%)$ e casadas $(47,6 \%)$. No entanto, em termos comparativos por idade houve diferenças significativas entre as mulheres "maduras" (77,3\% são casadas) e as "jovens" (68,3\% são solteiras). O nível de significância identificado com a aplicação do teste qui-quadrado confirma a diferença relacionada ao estado civil entre mulheres "maduras" e "jovens".

Ao longo das últimas décadas, a participação feminina na força de trabalho tem crescido. Este expressivo aumento é reflexo de uma série de alterações na sociedade, que passou a reconhecer e a se beneficiar da capacidade intelectual das mulheres (Lameiras, 2013). Neste sentido, o status do trabalho das respondentes do questionário, tanto em termos totais e categorizados por idade, são apresentados na Tabela 3. 
Tabela 3: Status do trabalho

\begin{tabular}{|c|c|c|c|}
\hline Status & $\%$ & Maduras & Jovens \\
\hline Empregada em Empresas de Serviços Contábeis & 39,7 & 36,4 & 41,5 \\
Empregada fora de Empresas de Serviços Contábeis & 54,0 & 59,1 & 51,2 \\
Não trabalha & 6,3 & 4,5 & 7,3 \\
\hline Total & 100 & 100 & 100 \\
\hline \multicolumn{2}{|c|}{ Teste Qui-quadrado (X) } & 0,43 \\
\hline \multicolumn{2}{|c|}{ Nível de Significância $(p)$} & 0,81 \\
\hline
\end{tabular}

Fonte: Elaborada pelas autoras.

Observou-se que existem diferenças relacionadas à proporção de mulheres empregadas tanto em uma empresa de Contabilidade (36,4\% de mulheres "maduras" e 41,5\% para as "jovens") ou empregadas fora de uma empresa contábil ( $59,1 \%$ das "maduras" e 51,2\% para as "jovens"). Das participantes da pesquisa, 6,3\% atualmente não trabalham. Verifica-se que o nível de significância é superior a 0,05, o que indica que não há diferenças significativas estatisticamente do status do trabalho entre as mulheres "maduras" e"jovens".

Diversas pesquisas apontam que ainda existe preconceito na profissão contábil com mulheres que têm filhos (Ciancanelli et al., 1990; Maupin, 1993; Barker \& Monks, 1998). O status atual das entrevistadas, categorizados pela idade, maternidade e regimes de trabalho são apresentados na Tabela 4. Os resultados revelam que a percentagem mais elevada de mulheres com filhos trabalham fora de Empresas de Serviços Contábeis (60\%), somente 35\% destas mulheres trabalham em Escritórios de Contabilidade.

Tabela 4: Status do trabalho categorizados por idade, regime de trabalho e maternidade

\begin{tabular}{|c|c|c|c|c|c|c|c|c|}
\hline \multirow{2}{*}{ Status } & \multirow{2}{*}{ Total } & \multicolumn{2}{|c|}{ Idade } & \multicolumn{2}{c|}{ Regime de Trabalho } & \multicolumn{2}{c|}{ Maternidade } \\
\cline { 4 - 10 } & & Maduras & Jovens & TP & TI & HF & Tem Filhos & Sem filhos \\
\hline Empregada em Empresa Contábil & 39,7 & 36,4 & 41,5 & 0 & 45,5 & 30 & 35 & 41,9 \\
Empregada fora Empresa Contábil & 54,0 & 59,1 & 51,2 & 100 & 54,5 & 70 & 60 & 51,1 \\
Não trabalha & 6,3 & 4,5 & 7,3 & 0 & 0 & 0 & 5 & 7 \\
\hline
\end{tabular}

* TP=Tempo parcial $T I=$ Tempo Integral HF=Horários flexiveis

Fonte: Elaborada pelas autoras.

As influências da estrutura, atributos e atitudes se combinam para criar uma barreira na progressão da carreiras das mulheres contadoras. No entanto, Altman e Simpson (2000) sugerem que essas barreiras podem ser perfuradas por mulheres "jovens". A posição das mulheres contadoras categorizados pela idade, é apresentado na Tabela 5: 
Tabela 5: Posição das entrevistadas dentro da empresa

\begin{tabular}{|c|c|c|c|}
\hline Posição & Total & Maduras & Jovens \\
\hline Cargo de direção & 3,2 & 0,0 & 4,9 \\
\hline Área fiscal & 17,5 & 9,1 & 22,0 \\
\hline Área contábil & 39,7 & 36,4 & 41,5 \\
\hline Recursos humanos & 4,8 & 9,1 & 2,4 \\
\hline Finanças corporativas & 7,9 & 13,6 & 4,9 \\
\hline Sócia/Autônoma & 17,5 & 27,3 & 12,0 \\
\hline Docência & 4,8 & 4,5 & 4,9 \\
\hline Auditoria & 4,8 & 0,0 & 7,3 \\
\hline Total & 100 & 100 & 100 \\
\hline \multicolumn{3}{|c|}{ Teste Qui-quadrado $\left(\mathrm{X}^{2}\right)$} & 8,72 \\
\hline \multicolumn{3}{|c|}{ Nível de Significância (p) } & 0,27 \\
\hline
\end{tabular}

Fonte: Elaborada pelas autoras.

Existem evidências a partir da amostra que apenas 20,7\% das mulheres já atingiram cargos gerenciais ou são donas do próprio negócio. Mais da metade das mulheres trabalham na área contábil ou fiscal. No entanto, quando esta amostra é desconstruída em subconjuntos relacionados a idade, uma série de resultados interessantes surgem. A totalidade de mulheres que ocupam cargos gerenciais são "jovens", o que corrobora com Altman e Simpson (2000). No entanto, o baixo percentual de mulheres "jovens" que alcançaram cargos gerenciais, sugere que elas ainda não têm alcançado o seu potencial de ocupar cargos de níveis gerenciais (Gammie et al., 2007). Isso corrobora com os achados de Altoé (2014), que os cargos de atuação das mulheres contadoras no Paraná são de auxiliar contábil, assistente contábil e analista contábil.

Deste modo, constata-se que a atuação da mulher contabilista está localizada em níveis hierárquicos mais baixos dentro das organizações. Constatou-se que o nível de significância é superior a 0,05, o que indica que não há diferenças significativas entre as respostas das mulheres "maduras" $\mathrm{e}$ "jovens".

\subsection{Estrutura Social}

Neste item, consideram-se o tipo de auxílio externo utilizado pelas respondentes durante o período da infância de seus filhos, classificados de acordo com a idade dos filhos, conforme apresentado na Tabela 6: 
Tabela 6: Os cuidados infantis

\begin{tabular}{|c|c|c|c|c|c|c|c|c|c|c|c|}
\hline Idade filhos & Idade & Babá TP & Babá TI & Auxílio família & Creche & Escolas infantis & TTP & IC & Nunca Utilizei & $X^{2}$ & $p$ \\
\hline Infantil & Maduras & 9,1 & 9,1 & 22,7 & 22,7 & 4,5 & 9,1 & 9,1 & 9,1 & 7,3 & 0,4 \\
& Jovens & 2,4 & 2,4 & 29,3 & 29,3 & 9,8 & 26,8 & 26,8 & 7,3 & & \\
Maternal & Maduras & 4,5 & 9,1 & 22,7 & 22,7 & 18,2 & 18,2 & 18,2 & 9,1 & 2,1 & 0,9 \\
& Jovens & 4,9 & 2,4 & 22,0 & 22,0 & 17,1 & 24,4 & 24,4 & 7,3 & & \\
\multirow{2}{*}{ Ensino Fund. I } & Maduras & 4,5 & 0,0 & 18,2 & 18,2 & 50,0 & 13,6 & 13,6 & 9,1 & 4,9 & 0,6 \\
& Jovens & 4,9 & 2,4 & 19,5 & 19,5 & 36,6 & 24,4 & 24,4 & 7,3 & & \\
\multirow{2}{*}{ Ensino Fund. III Maduras } & 0,0 & 0,0 & 22,7 & 22,7 & 45,5 & 18,2 & 18,2 & 9,1 & 5,9 & 0,5 \\
& Jovens & 4,9 & 4,9 & 17,1 & 17,1 & 36,6 & 24,4 & 24,4 & 7,3 & & \\
\end{tabular}

* TP=Tempo parcial $T I=$ Tempo integral TTP=Trabalho em tempo parcial IC=Interrupção Carreira

Fonte: Elaborada pelas autoras.

$\mathrm{Na}$ fase infantil, o auxílio para os cuidados infantis que mais foram utilizados pelas mulheres "maduras" são o auxílio da família (22,7\%), seguido da interrupção na carreira e a creche, com 18,2\%. Em contrapartida, as mulheres "jovens", nesta fase, utilizaram o auxílio da família (29,3\%) e do trabalho em tempo parcial $(26,8 \%)$ nesta fase. Tais resultados convergem com o que é difundido na literatura, de que a geração Y recorre a arranjos de trabalho flexíveis (Catalyst, 2001). Já na fase do maternal, 22,7\% das mulheres "maduras" contaram com o apoio da família. No entanto, a resposta das mulheres "jovens" foi o trabalho em tempo parcial $(24,4 \%)$, novamente.

Na fase da educação Ensino fundamental I e ll, as contadoras utilizaram as escolas infantis e o trabalho em tempo parcial, independente da idade das mulheres. Gammie et al (2007) relata que as mulheres "jovens" são mais propensas a procurar ajuda externa para atender aos cuidados com os filhos. Constata-se que na fase infantil, 18,2\% das mulheres "maduras" interrompem sua carreira em comparação as "jovens", que somente 7,3\% param de trabalhar neste período. Nota-se também que a maior parte das mulheres "jovens" optou por trabalhar em tempo parcial, em vez de interromper a carreira. Desta forma, percebe-se que as mulheres "jovens" não interrompem sua carreira após a maternidade, em geral, pela dificuldade de reinserção no mercado de trabalho.

Blätten-Mink, Kramer e Misschau (2000) argumentam que as mulheres "jovens" têm atitudes e expectativas diferentes das "maduras", e que as mudanças na educação e na cultura da sociedade têm facilitado a compatibilidade dos compromissos de trabalho com os familiares. Dessa forma, as percepções das contadoras em relação às questões de responsabilidade familiar, estão descritas na Tabela 7:

Tabela 7: Percepção das mulheres contadoras sobre sua responsabilidade familiar

\begin{tabular}{|c|c|c|c|c|c|c|}
\hline Afirmações & Idade & Concordo & Discordo & Indiferente & $\mathrm{X}^{2}$ & $p$ \\
\hline As mulheres não progridem na carreira igual aos homens, pois & Maduras & 68,2 & 31,8 & 0,0 & 7,5 & 0,0 \\
\hline escolhem priorizar a sua vida pessoal e familiar & Jovens & 36,6 & 46,3 & 17,1 & & \\
\hline \multirow[t]{2}{*}{ É difícil conciliar uma carreira com as responsabilidades familiares } & Maduras & 77,3 & 18,2 & 4,5 & 1,7 & 0,4 \\
\hline & Jovens & 61,0 & 31,7 & 7,3 & & \\
\hline
\end{tabular}




\begin{tabular}{|c|c|c|c|c|c|c|}
\hline Se houver uma crise familiar, a mulher deve se afastar do trabalho & $\begin{array}{c}\text { Maduras } \\
\text { Jovens }\end{array}$ & $\begin{array}{l}22,7 \\
19,5\end{array}$ & $\begin{array}{l}72,7 \\
70,7\end{array}$ & $\begin{array}{l}4,5 \\
9,8\end{array}$ & 0,6 & 0,7 \\
\hline Eu coloco minha família a frente dos compromissos profissionais & $\begin{array}{c}\text { Maduras } \\
\text { Jovens }\end{array}$ & $\begin{array}{l}72,7 \\
63,4\end{array}$ & $\begin{array}{l}13,6 \\
22,0\end{array}$ & $\begin{array}{l}13,6 \\
14,6\end{array}$ & 0,7 & 0,7 \\
\hline O lugar da mulher é no lar & $\begin{array}{c}\text { Maduras } \\
\text { Jovens }\end{array}$ & $\begin{array}{l}0,0 \\
7,3\end{array}$ & $\begin{array}{r}100 \\
85,4\end{array}$ & $\begin{array}{l}0,0 \\
7,3\end{array}$ & 3,6 & 0,2 \\
\hline $\begin{array}{c}\text { É necessário sacrificar tempo com a família pelos compromissos } \\
\text { profissionais para assegurar o cumprimento de prazos }\end{array}$ & $\begin{array}{c}\text { Maduras } \\
\text { Jovens }\end{array}$ & $\begin{array}{l}63,6 \\
41,5\end{array}$ & $\begin{array}{l}22,7 \\
41,5\end{array}$ & $\begin{array}{l}13,6 \\
17,1\end{array}$ & 2,9 & 0,2 \\
\hline
\end{tabular}

Fonte: Elaborada pelas autoras.

Destaca-se que, a maioria das mulheres pesquisadas discordam da afirmativa de que o lugar da mulher é dentro de casa. Entretanto, a maioria das mulheres "maduras", concordaram que "as mulheres não progridem na carreira igual aos homens, pois escolhem priorizar a sua vida pessoal e familiar", em contrapartida 46,3\% das "jovens" que discordam desta afirmativa. Verificou-se também que as mulheres "maduras" estavam dispostas a se dedicar exclusivamente para a família, pois, a maioria das respondentes relatou que era necessário sacrificar o tempo com a família para garantir o cumprimento dos compromissos profissionais (63,6\%). Isso se deve pela dificuldade dessas mulheres em conciliar sua carreira com as responsabilidades familiares (77,3\% das mulheres "maduras" e 61,0\% das "jovens" concordaram com esta afirmativa). De acordo com Gammie et al. (2007), as mulheres devem desafiar seus patrões a fornecer um ambiente de trabalho propício para um work-life balance, sem serem coagidas a priorizar o trabalho sobre a família.

No entanto, essa aparente aceitação por mulheres que colocam sua família a frente dos compromissos profissionais não permanece em tempos de crise (com rejeição de 72,7\% das "maduras"e 70,7\% para as "jovens"). Isto sugere que, quando existe uma crise conjugal há relutância das mulheres em assumirem o papel de chefes de família.

Ressalta-se que um dos principais aspectos que contribui para a falta de oportunidades profissionais das contadoras é o estereótipo de que as mulheres que têm filhos não estão comprometidas com a organização (Maupin, 1993; Hooks, Gammie e Gammie, 1995; Windsor \& Auyeung, 2006) e são menos propensas de fazer as horas extras necessárias para obter uma promoção (Barker \& Monks, 1998; Windsor \& Auyeung, 2006). Neste sentido, verificou-se qual a percepção das respondentes a respeito dos requisitos para trabalhar por longas horas, conforme Tabela 8: 
Tabela 8: Requisitos para trabalhar por longas horas

\begin{tabular}{|c|c|c|c|c|c|c|}
\hline \multicolumn{7}{|c|}{ Painel A - Idade } \\
\hline Descrição & Idade & Concordo & Discordo & Indiferente & $\mathrm{X}^{2}$ & $p$ \\
\hline Para ser bem sucedida você precisa & Maduras & 40,9 & 36,4 & 22,7 & 1,78 & 0,4 \\
\hline trabalhar por longas horas & Jovens & 31,7 & 53,7 & 14,6 & & \\
\hline A profissão de contador privilegia uma & Maduras & 36,4 & 31,8 & 31,8 & 4,92 & 0,1 \\
\hline cultura machista & Jovens & 43,9 & 46,3 & 9,8 & & \\
\hline \multicolumn{7}{|c|}{ Painel B - Mulheres casadas e com filhos } \\
\hline Descrição & Idade & Concordo & Discordo & Indiferente & $\mathrm{X}^{2}$ & $p$ \\
\hline Para ser bem sucedida você precisa & Maduras & 42,9 & 35,7 & 21,4 & 0,16 & 0,9 \\
\hline trabalhar por longas horas & Jovens & 50,0 & 25,0 & 25,0 & & \\
\hline A profissão de contador privilegia uma & Maduras & 42,9 & 35,7 & 21,4 & 2,19 & 0,33 \\
\hline cultura machista & Jovens & 25,0 & 75,0 & 0,0 & & \\
\hline
\end{tabular}

Fonte: Elaborado pelas autoras.

Nota-se que, a maioria das mulheres "jovens" pesquisadas discordaram com a proposição que para ter sucesso se faz necessário trabalhar por longas horas. No entanto, ao analizar somente as mulheres casadas e com filhos, verifica-se que a maioria das mulheres "jovens" concordam com esta afirmativa. Embora, 46,3\% das mulheres "jovens" discordaram com o sentimento de que profissão de contador privilegia uma cultura machista, pouco menos da metade das mulheres "maduras" concordam (36,4\%). Observou-se que, quase a totalidade das mulheres casadas e com filhos discordam desta afirmativa. Os achados da pesquisa, são contrários a pesquisa de Gammie et al. (2007) em que a maioria das mulheres escocesas concordam com a proposição de que "para ser bem sucedida você precisa trabalhar por longas horas" e "a profissão de contador privilegia uma cultura machista". Essa diferença de percepção entre as mulheres escocesas e as brasileiras do estado do Paraná é que no Reino Unido a profissão contábil está bem consolidada e os movimentos feministas estabelecidos (Ramdhony, Oogarah-Hanuman e Somir; 2013).

Verifica-se que as Empresas de Serviços Contábeis brasileiras têm tido algumas mudanças de sua cultura organizacional em relação as mulheres. Constatou-se que o nível de significância em todos os casos é superior a 0,05, o que indica que não há diferenças significativas de percepção entre as respostas das mulheres "maduras" $\mathrm{e}$ "jovens". Da mesma forma, houve rejeição pelas pesquisadas à sugestão de que é impossível progredir na carreira contábil trabalhando em tempo parcial, como evidenciado na Tabela 9. 
Tabela 9: Percepções do impacto por trabalhar em tempo parcial

\begin{tabular}{|c|c|c|c|c|c|c|}
\hline Descrição & Idade & Concordo & Discordo & Indiferente & $X^{2}$ & $p$ \\
\hline É impossível progredir na carreira con-Maduras & $\begin{array}{c}22,7 \\
29,3\end{array}$ & $\begin{array}{c}54,5 \\
43,9\end{array}$ & 22,7 & 0,21 & 1,0 \\
tábil trabalhando em tempo parcial & Jovens & & & & \\
\hline
\end{tabular}

Fonte: Elaborada pelas autoras.

Constatou-se que a maioria das mulheres "maduras" (54,5\%) discordam com o sentimento de que é impossível progredir na carreira contábil trabalhando em tempo parcial, e com uma percentagem ligeiramente menor, as mulheres “jovens" também discordam (43,9\%) com esta afirmativa. Isto sugere que as mulheres estão em busca de políticas específicas para ajudar o equilíbrio entre vida profissional e familiar, tais como: flexibilidade de horários de trabalho e interrupções de carreira programadas. Verifica-se que o nível de significância é superior a 0,05 , o que indica que não há diferenças significativas de percepção entre as pesquisadas "maduras" e "jovens".

\subsection{Cultura organizacional}

Diversas pesquisas sugerem que muitas organizações estavam introduzindo políticas de work life balance para criar flexibilidade no local de trabalho (Barker \& Monks, 1998; Gammie et al., 2007). Por isso, a disponibilidade de formas de trabalho flexíveis na profissão da mulher contabilista foi considerada, conforme mostra a Tabela 10.

Tabela 10: Percepção e experiências sobre as práticas de trabalho flexíveis

\begin{tabular}{|c|c|c|c|c|c|c|c|}
\hline $\begin{array}{c}\text { Esquema trabalho } \\
\text { Flexível }\end{array}$ & Participo & Não & $\begin{array}{c}\text { Gostaria de participar, } \\
\text { mas pode impedir } \\
\text { meu progresso }\end{array}$ & $\begin{array}{l}\text { Disponível e } \\
\text { posso optar } \\
\text { se necessário }\end{array}$ & $\begin{array}{l}\text { Não estou } \\
\text { interessado }\end{array}$ & $X^{2}$ & $p$ \\
\hline Horários flexíveis & 15,9 & 68,3 & 1,6 & 9,5 & 4,8 & 0,7 & 0,7 \\
\hline Trabalho em tempo parcial & 22,2 & 44,4 & 1,6 & 9,5 & 22,2 & 2,1 & 2,1 \\
\hline $\begin{array}{c}\text { Compensação horas para folgar em } \\
\text { feriados longos }\end{array}$ & 34,9 & 17,5 & 4,8 & 33,3 & 9,5 & 0,2 & 0,2 \\
\hline
\end{tabular}

Fonte: Elaborada pelas autoras.

Quanto a forma de trabalho flexível mais popular na profissão contábil é a compensação de horas para folgar em feriados longos, com 34,9\% de participação, seguido do trabalho em tempo parcial, com $22,2 \%$. Verifica-se que, $22,2 \%$ das mulheres não tem interesse em trabalhar por meio período, o que pode estar relacionado ao fato de as empresas não incentivarem este regime de trabalho. Altoé (2014) ressalta que no caso do gênero feminino o acúmulo de tarefas prevalecem, pois a maioria das mulheres contadoras paranaenses são mães, esposas, trabalham fora e ainda realizam atividades domésticas. Deste modo, as empresas devem considerar estas práticas de work-life balance.

Diversas pesquisas sugerem que existem redes de trabalho (networking) masculinas nos escritórios de Contabilidade, o que poderia resultar em uma falta de oportunidade e um sentimento de isolamento pelas mulheres (Gammie \& Gammie; 1995; Altman \& Simpson, 2000; Gammie et al. 2007). As experiências dos contadoras mulheres pesquisadas em relação ao networking são apresentadas na Tabela 11. 
Tabela 11: Percepções e experiências sobre networking

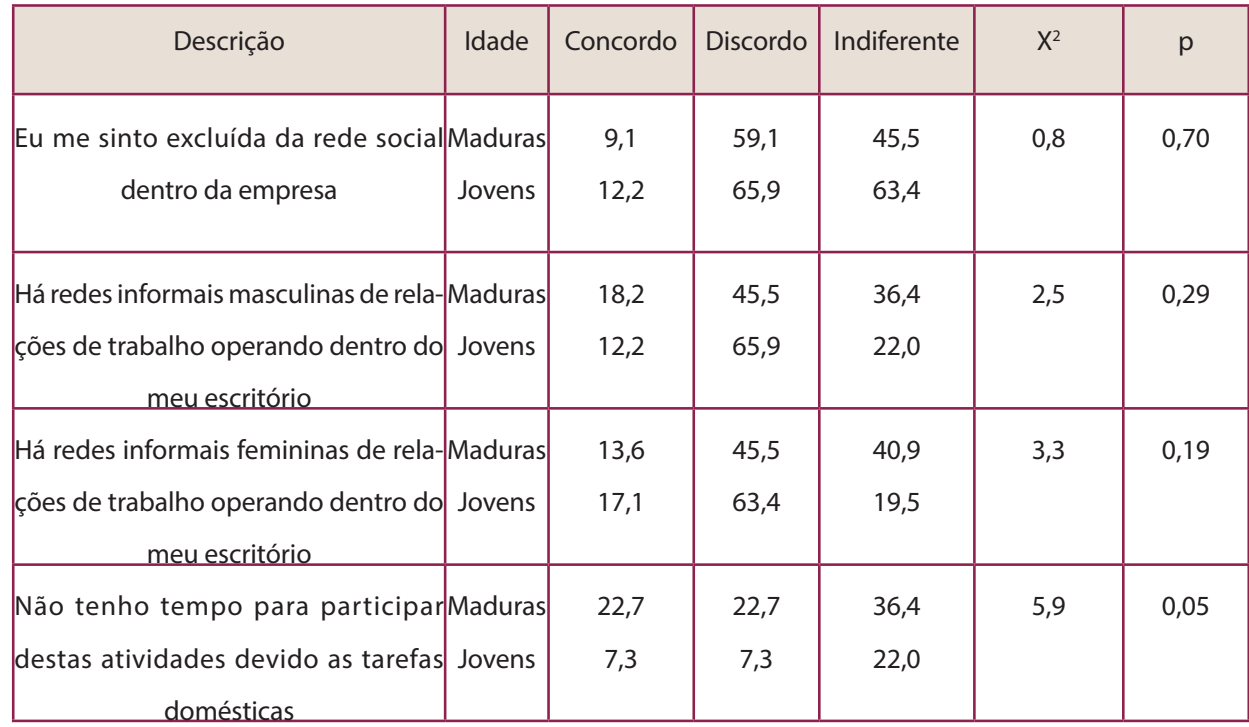

Fonte: Elaborada pelas autoras.

Por sua vez, a maioria das mulheres discordaram da afirmação que se sentiam excluídas das redes sociais dentro de seu ambiente de trabalho, embora uma maior percentagem de mulheres discordaram que havia redes masculinas informais que operam dentro de seus escritórios (45,5\% de mulheres "maduras" e 65,9\% das mulheres "jovens" concordaram com este). Com relação ao tempo destinado as atividades de networking, 40,9\% das mulheres "maduras" concordam que as tarefas domésticas atrapalham estas atividades, em oposição a "jovens" discordam desta afirmativa. Bryson (1992) relata que os homens são competidores natos e agressivos, enquanto a mulheres são mais sentimentais e suscetíveis de serem influenciadas pela existência ou não de redes sociais dentro de seu ambiente de trabalho. Constatou-se que as diferenças são significativas de percepção e experiências entre as pesquisadas "maduras" e"jovens" para a última assertiva.

\subsection{Por que as mulheres deixam de trabalhar em Empresas de Serviços Contábeis?}

Estudos realizados em escritórios de Contabilidade revelam a existência de um complexo processo de socialização interna, que molda a identidade dos profissionais que trabalham nestes ambientes. Esse processo age como um mecanismo a fim de excluir as mulheres, impedir o seu progresso e facilitar a sua saída (Gammie \& Whiting, 2013). Neste trabalho, procurou-se analisar os fatores que influenciam as mulheres pesquisadas para deixar de trabalhar em empresas de Contabilidade e seguir uma carreira fora deste ambiente. Dessa forma, foi solicitado as respondentes que enumerassem em ordem decrescente as possíveis razões para deixar de trabalhar em Escritórios de Contabilidade, conforme a Tabela 12. 
Tabela 12: Razões para deixar de trabalhar em escritórios de Contabilidade

\begin{tabular}{|c|c|c|c|c|c|c|c|}
\hline & Menos influente & & & & Mais influente & Total & Média \\
\hline Razões para sair & 1 & 2 & 3 & 4 & 5 & & \\
Um trabalho mais interessante & 7,9 & 11,1 & 14,3 & 23,8 & 42,9 & 100 & 3,83 \\
Melhor ambiente de trabalho & 9,5 & 8 & 23,8 & 25,4 & 33,3 & 100 & 3,65 \\
Progressão da carreira profissional & 4,8 & 6,3 & 7,9 & 30,2 & 50,8 & 100 & 4,16 \\
Melhor remuneração & 6,3 & 0 & 1,7 & 33,3 & 58,7 & 100 & 4,38 \\
Mais flexibilidade & 17,5 & 9,5 & 12,7 & 19 & 41,3 & 100 & 3,57 \\
& & & & & & & \\
\hline
\end{tabular}

Fonte: Elaborada pelas autoras.

Diante dos dados, depreende-se que a razão mais influente para as mulheres decidirem por saírem da profissão contábil é a melhor remuneração (média 4,38), seguida por oportunidades de progredir na carreira (média 4,16). A razão menos influente foi a flexibilidade (média 3,57). Estes resultados devem causar alguma preocupação para as empresas de Contabilidade, pois o motivo da saída destas profissionais parece ser conseqüência da falta de valorização e baixa remuneração dessas organizações. Gammie e Whiting (2013) investigaram se as práticas dos escritórios de Contabilidade influenciam as mulheres contadoras filiadas ao ICAS em buscar alternativas de emprego fora deste ambiente de trabalho. Os resultados encontrados corroboram com a falta de valorização da mulher, pois a principal razão das mulheres deixarem essas empresas é para buscar um trabalho mais interessante, ao invés de obter maior flexibilidade no seu trabalho.

\subsection{Por que as mulheres criam seu próprio negócio?}

Neste item, foi solicitado para as mulheres classificarem, em ordem de influência, as razões para a criação de seu próprio negócio. Dessa forma, foi solicitado as respondentes que enumerassem em ordem decrescente as possíveis razões para criarem o seu próprio negócio. Os resultados estão contidos na Tabela 13.

Tabela 13: Razões para a criação de negócio próprio

\begin{tabular}{|c|c|c|c|c|c|c|c|}
\hline Posição & Menos influente & & & & Mais influente & Total & Média \\
\hline Razões para criar próprio negócio & 1 & 2 & 3 & 4 & 5 & & \\
Mais flexibilidade & 3 & 1 & 1 & 15 & 43 & 63 & 4,5 \\
Melhor ambiente de trabalho & 2 & 2 & 9 & 18 & 32 & 63 & 4,2 \\
Um trabalho mais interessante & 4 & 4 & 11 & 14 & 30 & 63 & 4,0 \\
Melhor remuneração & 4 & 3 & 5 & 21 & 30 & 63 & 4,1 \\
\hline
\end{tabular}

Fonte: Elaborada pelas autoras.

A Tabela 14 demonstra que a razão para a criação de seu próprio negócio foi a flexibilidade (média 4,49), citando este como o fator mais influente na decisão. Em contrapartida, a flexibilidade foi razão menos influente para as mulheres saírem das empresas de Contabilidade. Como análise complementar, buscou-se verificar, também, as razões para as mulheres que criaram o seu próprio negócio. 
Os resultados encontrados foram semelhantes ao da amostra total, em que flexibilidade (média 4,6) e ambiente de trabalho (média 4,6) são as razões mais influentes. Estes resultados estão de acordo com os achados de Gammie et al. (2007), em que a principal razão para a criação do seu próprio negócio era obter uma maior flexibilidade.

\subsection{Análise da hipótese da pesquisa}

Considerando a progressão, percepções e experiências das mulheres contadoras pesquisadas frente as questões apresentadas a partir da discussão dos tópicos questões demográficas, cultura social, cultura organizacional das empresas, porque as mulheres deixam de trabalhar em escritórios de Contabilidade e, finalmente, as razões para elas criarem seu próprio negócio, passa-se à análise da hipótese da pesquisa:

H1: As mulheres contadoras mais "jovens" estão rompendo o glass ceiling na busca pela progressão na carreira contábil.

As barreiras invisíveis que compõem o glass ceiling incluem uma miríade de barreiras de comportamento que estão inter-relacionados com as barreiras contextuais que emanam da cultura social e organizacional em que as mulheres estão inseridas. Assim, apesar de alguns elementos sugerirem o progresso das mulheres contadoras em algumas áreas, outras barreiras continuam a impedir seu avanço.

Contatou-se que o nível de significância das respostas das mulheres contadoras pesquisadas, em geral, não apresentou resultado significativo, demonstrando não ser possível apresentar diferença estatisticamente de percepção entre as mulheres "maduras" e“jovens", conforme mostra a Tabela 14.

Tabela 14: Teste Qui-Quadrado

\begin{tabular}{|c|c|c|}
\hline SEÇÖES & Chi-Square & $\mathrm{p}$ \\
\hline \multicolumn{3}{|l|}{ Questões demográficas } \\
\hline Estado civil & 15,18 & 0,01 \\
\hline Status do trabalho & 0,43 & 0,81 \\
\hline A maternidade & 0,44 & 0,80 \\
\hline Posição dentro da empresa & 8,72 & 0,27 \\
\hline \multicolumn{3}{|l|}{ Cultura social } \\
\hline As mulheres não progridem na carreira igual aos homens & 7,49 & 0,02 \\
\hline É difícil conciliar uma carreira com as responsabilidades familiares & 1,71 & 0,42 \\
\hline Se houver uma crise familiar, a mulher deve se afastar do trabalho & 0,57 & 0,75 \\
\hline Eu coloco minha família a frente dos compromissos profissionais & 0,72 & 0,70 \\
\hline O lugar da mulher é no lar & 3,56 & 0,17 \\
\hline É necessário sacrificar tempo com a família pelos compromissos profissionais & 2,98 & 0,23 \\
\hline Para ser bem sucedida você precisa trabalhar por longas horas & 1,78 & 0,41 \\
\hline A profissão de contador privilegia uma cultura machista & 4,92 & 0,08 \\
\hline É impossível progredir na carreira contábil trabalhando em tempo parcial & 0,21 & 1,00 \\
\hline \multicolumn{3}{|l|}{ Cultura organizacional } \\
\hline Eu me sinto excluída da rede social dentro da empresa & 0,77 & 0,68 \\
\hline Há redes informais masculinas de relações de trabalho & 2,48 & 0,29 \\
\hline Há redes informais femininas de relações de trabalho & 3,34 & 0,19 \\
\hline Não tenho tempo para participar destas atividades devido as tarefas domésticas & 5,89 & 0,05 \\
\hline
\end{tabular}

Fonte: Elaborada pelas autoras. 
Os resultados do teste de médias sugerem que as mulheres "jovens" discordam que a profissão contábil privilegia uma cultura "machista". O nível de significância de 10\%, confirma a diferença relacionada a diferença de percepção entre as mulheres "maduras" $e$ "jovens". Outro resultado relevante refere-se que as mulheres "jovens" também discordam que as mulheres não progridem na carreira igual aos homens, com nível de significância de 2\%. De acordo com Gammie et al. (2007), as mulheres devem desafiar seus patrões a fornecer um ambiente de trabalho propício para um work-life balance, para que mulheres tenham as mesmas possibilidades que os homens e consigam chegar a cargos de poder.

Embora, existam mudanças culturais em relação às responsabilidades das mulheres no momento de crise familiar, na utilização de auxílio externo para o cuidado com os filhos (escolas, creches, etc.) e o aumento da licença maternidade, pouco progresso tem sido feito em relação a outros aspectos. As empresas continuam a adotar uma cultura "machista", principalmente em relação ao regime de trabalho, e isso restringe as escolhas as profissionais do sexo feminino, uma vez que é considerado impossível alcançar um work-life balance dentro do ambiente de uma empresa de Contabilidade.

Verifica-se que a hipótese $\mathrm{H} 1$ é rejeitada para o nível de significância estipulado (5\%). Assim, não se pode afirmar que existe diferença na progressão da carreira entre as mulheres contadoras "jovens" e as "maduras". Os resultados indicaram que as mulheres "jovens" $\mathrm{e}$ "maduras" ainda estão enfrentando o glass ceiling em sua busca de progressão dentro do local de trabalho. Apesar do movimento em direção a uma maior igualdade de direitos na sociedade em termos de responsabilidades domésticas e familiares e a maior possibilidade de escolha das mulheres, seu progresso profissional em cargos de nível gerencial ainda tem sido limitado.

Os achados da pesquisa corroboram com Gammie et al. (2007), que relatam que o glass ceiling ainda pode estar presente para as mulheres contadoras. No entanto, há pesquisas que identificam que o glass ceiling está deixando de existir, especialmente em algumas áreas "especializadas" como auditoria (Whiting \&Wright, 2001). No entanto, os autores acreditam que o glass ceiling ainda não é coisa do passado, e várias questões ainda precisam ser endereçadas em relação à progressão das mulheres na profissão contábil.

\section{CONSIDERAÇÕES FINAIS}

A literatura destaca que as mudanças sociais e organizacionais podem contribuir para o rompimento do glass ceiling (Gammie et al., 2007; Altman \& Simpson, 2000). Os resultados deste estudo, portanto, foram discutidos, em termos das mudanças na cultura social, seguido por uma reflexão sobre o impacto de eventuais mudanças na cultura organizacional, para o progresso das mulheres. As questões demográficas também são consideradas nesta discussão.

A divisão da amostra deste estudo em mulheres "maduras" (com pelo menos 30) e mulheres "jovens" (com idade até 29) revela que a totalidade de mulheres que ocupam cargos gerenciais são "jovens", o que corrobora com Altman e Simpson (2000). No entanto, o baixo número de mulheres "jovens" que alcançaram cargos gerenciais, sugere que elas ainda não têm alcançado o seu potencial de ocupar cargos de níveis gerenciais (Gammie et al., 2007). Cerca de metade das mulheres pesquisadas trabalham na área contábil ou fiscal. 
A divisão da amostra deste estudo em mulheres "maduras" (com pelo menos 30) e mulheres "jovens" (com idade até 29) revela que a totalidade de mulheres que ocupam cargos gerenciais são "jovens", o que corrobora com Altman e Simpson (2000). No entanto, o baixo número de mulheres "jovens" que alcançaram cargos gerenciais, sugere que elas ainda não têm alcançado o seu potencial de ocupar cargos de níveis gerenciais (Gammie et al., 2007). Cerca de metade das mulheres pesquisadas trabalham na área contábil ou fiscal.

Assim, as mulheres mais jovens não estão rompendo o glass ceiling e chegando ao topo da maneira sugerida por pesquisadores no início e meados da década de 1990. As evidências deste estudo replicam a tendência de que as mulheres estejam se casando e tendo filhos mais tarde na vida. Há também evidências de mudanças culturais dentro da sociedade. Por exemplo, havia uma percepção de que seja cada vez mais aceitável para as mulheres voltar ao trabalho após a maternidade, mesmo que em tempo parcial, e utilizar creche ou escolas infantis. Há também indícios de mudança da sociedade em relação a responsabilidades familiares, em que as mulheres parecem esperar mais igualdade em tempos de crise familiar de seus cônjuges.

Outro ponto de reflexão foi o de que a maioria das mulheres que trabalham em Empresas de Serviços Contábeis estão sobre o regime de trabalho integral. Assim, apesar dos potenciais benefícios que podem advir para as empresas que tentam oferecer um work-life balance aceitável para as suas funcionárias, em geral, mantiveram sua cultura "machista" em relação ao regime de trabalho. Isso parece ser universal em todas as empresas em disponibilizar apenas formas tradicionais de trabalho flexível, tais como compensação de horas para folgar em feriados longos, com 34,9\% de participação, seguido do trabalho em tempo parcial, com $22,2 \%$.

Ao longo da última década, a crescente conscientização sobre o glass ceiling incentivou a criação de políticas específicas na tentativa de romper essa barreira (Gammie et al., 2007). Dessa forma, as empresas de Contabilidade necessitam reter, desenvolver e promover as mulheres contadoras. No entanto, apenas $36,4 \%$ mulheres "maduras" e 41,5\% das "jovens" trabalham em empresas de Contabilidade e isso sugere que algum atrito pode ter ocorrido. Mais da metade das respondentes do questionário trabalham fora dos escritórios e somente $6,3 \%$ não trabalham. A razão mais influente para as mulheres decidirem saírem da profissão contábil é a melhor remuneração (média 4,38), e não buscar uma maior flexibilidade, que é identificada como a razão menos influente. Isto está em contraste com as mulheres que buscam criar seu próprio negócio, pois a razão mais influente é a maior flexibilidade (média 4,49). Assim, embora as Empresas de Serviços Contábeis percam algumas mulheres que têm interrupções de carreira e, em seguida, optaram por não voltar a trabalhar, a maior perda são mulheres em busca de uma maior remuneração e flexibilidade. Esses achados devem ser considerados se as empresas quiserem reter talentos femininos.

Desta forma, e de acordo com Gammie et al. (2007), as barreiras invisíveis que compõem o glass ceiling incluem uma miríade de barreiras de comportamento que estão inter-relacionados com as barreiras contextuais que emanam da cultura social e organizacional em que as mulheres estão inseridas. Assim, apesar de alguns elementos sugerirem o progresso das mulheres contadoras em algumas áreas, outras barreiras continuam a impedir seu avanço. Embora, existam mudanças culturais em relação às responsabilidades das mulheres no momento de crise familiar, na utilização de auxílio externo para o cuidado com os filhos (escolas, creches, etc.) e o aumento da licença maternidade, pouco progresso tem sido feito em relação a outros aspectos. 
As empresas continuam a adotar uma cultura "machista", principalmente em relação ao regime de trabalho, e isso restringe as escolhas as profissionais do sexo feminino, uma vez que é considerado impossível alcançar um work-life balance dentro do ambiente de uma empresa de Contabilidade. Assim, as mulheres "mais jovens" ainda estão enfrentando o glass ceiling em sua busca de progressão no trabalho. Apesar de um movimento em direção a uma maior igualdade na sociedade, em termos de responsabilidades domésticas e familiares, e uma sociedade que oferece as mulheres algum tipo de escolha, seu progresso tem sido limitado.

Os resultados desta pesquisa podem ser um ponto de partida para o desenvolvimento de novos estudos que tenham como objetivo a análise da desigualdade de gênero na profissão contábil no Brasil, que é ainda escassa, além de incentivar atitudes proativas das empresas na elaboração de práticas de trabalho flexíveis para as mulheres contadoras. Pesquisas futuras podem replicar este estudo em outras regiões do País. Outras investigações também poderiam verificar a progressão da mulher contadora categorizado pelo tempo de formação, ao invés da idade. Outro ponto de interesse é aprofundar a análise e observar também a progressão profissional dos contadores do sexo masculino do estado do Paraná e confrontar com os resultados encontrados.

Quanto as limitações da pesquisa, verifica-se que os achados são restritos as mulheres contadoras pesquisadas nas IES do estado do Paraná. Entretanto, os resultados não podem ser generalizados, ou seja, restringem-se à população investigada. Outro aspecto, é que a o número de mulheres jovens é maior que o de mulheres maduras, desta forma não pode haver generalizações. Destaca-se também como limitação da pesquisa, o pequeno número de respondentes, o que impossibilitou ampliar as alternativas de análise dos dados. Outra limitação refere-se à estratégia da pesquisa, que se fundamentou na percepção dos respondentes às questões formuladas. 


\section{REFERÊNCIAS}

Almer, E. \& Single, L. (2007). Shedding light on the AICPA work/life and women's initiatives research: What does it mean to educators and students? Issues in Accounting Education, 22(1), 67-77.

Altman, Y. \& Simpson, R. (2000). The time bounded glass ceiling and young women managers; career progress and career success. Journal of European Industrial Training, 24(20), 190-198.

Altoé, S. M. L. (2014). Fatores explicativos do work-life balance de contadores à luz da psicologia positiva. 136 f. Dissertação (Mestrado em Contabilidade) - Programa de Pós-Graduação em Contabilidade, Universidade Federal do Paraná, Curitiba, Brasil.

Barker, P. C. \& Monks, K. (1998). Irish women accountants and career progression: a research note. Accounting, Organizations and Society, 23(8), 813-823.

Bellodi, P. L. (2006). Vocação, profissão e personalidade: uma contribuição na área médica através do psicodiagnóstico de Rorschach. Avaliação Psicológica, 5(2), 69-273.

Blätten-Mink, B., Kramer, C. e Misschau, A. (2000). The attitudes of women towards the compatibility of family and employment. Equal Opportunities International. 19(1), 1-11.

Broadbent, J. \& Kirkham, L. (2008). Glass ceilings, glass cliffs or new worlds? Revisiting gender and accounting. Accounting, Auditing and Accountability Journal, 21(4), 465-473.

Bryson, V. (1992). Feminist political theory: an introduction. Macmillan: Basingstoke.

Cappellin, P. (2008). As desigualdades impertinentes: telhado, paredes ou céu de chumbo? Revista Gênero, 9(1), 89-126.

Casa Nova, S. P.C. (2012). Impactos de mestrados especiais em Contabilidade na trajetória de seus egressos: um olhar especial para gênero. Revista de Contabilidade e Controladoria, 4(3), 37-62.

Catalyst. (2001). The next generation: today's professionals, tomorro's leaders. Disponível em: <http:// www.catalyst.org/knowledge/next-generation-

today\%E2\%80\%99s-professionals-tomorrow\%E2\%80\%99s-leaders>. Acesso em: 02.05.2015.

Ciancanelli, P., Gallhofer, S., Humphrey, C. e Kirkham, L. (1990). Gender and accountancy: some evidence from the United Kingdom. Critical Perspectives on Accounting, 1(2), 117-144.

Childs, S.; Krook, M. L. (2008). Critical Mass Theory and Women's Political Representation. Political studies, $56,725-736$. 
Cooper, Donald. R. \& Schindler, Pamela S. (2003). Métodos de pesquisa em administração. 7. ed. Porto Alegre: Bookman.

Conger, J. (1998). Quem é a geração X? HSM Management, 11,128-138.

Crompton, R. (1987). Gender and accountancy: a response to Tinker and Neimark. Accounting, Organisations and Society, 12(1), 103-110.

Dambrin, C. \& Lambert, C. (2008). Mothering or auditing? The case of two Big Four in France. Accounting, Auditing and Accountability Journal, 21(4), 474-506.

Dahlerup, D. (1988). From a Small to a Large Minority: Women in Scandinavian Politics. Scandinavian Political Studies, 11(4), 275-297.

Devonport, B. (2007). Women in accounting: their careers and membership of the institute of chartered accountants in New Zealand. University of Canterbury, 2007.

French, S. \& Meredith, V. (1994). Women in public accounting: growth and advancement. Critical Perspectives on Accounting, 5(3), 227-241.

Gammie, E. \& Gammie, B. (1995). Women chartered accountants - progressing in the right direction? Women in Management Review, 10(1), 5-13.

Gammie, E., Gammie, B., Matson, M. e Duncan, F. (2007). Women of ICAS reaching the top: the demise of the glass ceiling. The Institute of Chartered Accountants of Scotland.

Gammie, E \& Whiting, R. (2013). Women accountants: Is the grass greener outside the profession? The British Accounting Review, 45, 83-98.

Hanlon, G. (1994). The commercialisation of accounting: flexible accumulation and the service class. London: MacMillan.

Hanlon, G. (1996). 'Casino capitalism' and the rise of the 'commercialised' service class - an examination of the accountant. Critical Perspectives on Accounting, 7(3), 343-366.

Hooks, B. (2014). Feminist Theory: From Margin to Center. Routledge.

Hooks, K. L. \& Cheramy, S. J. (1994). Facts and myths about women CPAs. Journal of Accountancy, 79-86.

Hultin, M. \& Szulkin, R. (1999). Wages and unequal access to organizational power: an empirical test of gender discrimination. Administrative Science Quarterly, 44(3), 453-472. 
Hymowitz, C. \& Schellhardt, T. (1986). The glass ceiling: why women can't seem to break the invisible barrier that blocks them from the top jobs. The Wall Street Journal, 24, 1-4.

IBGE - Instituto Brasileiro de Geografia e Estatística. (2013). Síntese de Indicadores Sociais: Uma análise das condições de vida da população brasileira. Rio de Janeiro. Disponível em: < ftp://ftp.ibge.gov.br/ Indicadores_Sociais/Sintese_de_Indicadores_Sociais_2012/SIS_2012.pdf>. Acesso em: 20 ago. 2014.

Jackson, J. Women middle managers perceptions of the glass ceiling. Women in Management Review, v. 16, n. 1, p. 30-41, 2001.

Judson, S. Opportunities and outcomes. Chartered Accountants Journal, p. 63-64, 1997.

Kanter, R. M. (1977a). Some Effects of Proportions on Group Life. American Journal of Sociology, 82(5), 965-90.

Kanter, R. M. (1977b). Men and Women of the Corporation. New York: Basic Books.

Kirkham, L. (1992). Integrating herstory and history in accounting. Accounting, Organizations and Society, $17,287-297$.

Lameiras, M. A. P. (2013). Efeitos da população economicamente ativa sobre a taxa de desemprego. IPEA.

Lamsa, A. M. \& Sintonen, T. A. (2001). Discursive approach to understanding women leaders in working life. Journal of Business Ethics, 34(3/4), 255-267.

Lehman, C. R. (1992). Herstory in accounting: The first eighty years. Accounting, Organizations and Society, $17,261-285$.

Lineham, M. \& Walsh, J. (1999). Senior female international managers; breaking the glass border. Women in Management Review, 14(7), 264-272.

Linehan, M., Scullion, H. e Walsh, J. (2001). Barriers to women's participation in international management. European Business Review, 13(1), 10-18.

Luca, M. M. M., Cornachione Junior, E. B., Cunha, J.V. A. e Ott, E. (2011). Associação de modelos de sucesso profissional e gênero entre graduandos de ciências contábeis. Advances in Scientific and Applied Accounting, São Paulo, 4(2), 263-284.

Maupin, R. J. (1993). Explaining the scarcity of women accounting partners: male and female accountants respond. Group and Organization Management, 18(2), 42-56.

Mckeen, C. A. \& Bujaki, M. L. (1994). Taking women into account. CA Magazine, Canada, March, 29-35. 
Mckeen, C. A. \& Richardson, A. J. (1998). Education, employment and certification: an oral history of the entry of women into the Canadian accounting profession. Business and Economic History, 27(2), 500-532.

Monks, K. \& Barker, P. (1996). The glass ceiling: cracked but not broken? evidence from a study of chartered accountants. DCUBS Research Paper Series, 1.

Morrison, A. \& Von Glinow, M. (1990) Women and minorities in management. American Psychologist, 200-208.

Okanlawon, G. (1994). Women as strategic decision makers: a reflection on organisational barriers. Women in Management Review, 9(4), 25-32.

Oliveira, Sidnei. (2009). Geração Y: Era das Conexões, tempo de Relacionamentos. São Paulo: Clube de Autores.

Pires, F. M., Lucas, A. C., Andrade, S. M., Fischer, A. L. e Amorim, W. A. C. (2010). Gênero e as Práticas de Gestão nas Melhores Empresas para se Trabalhar no Brasil. Revista Interinstitucional de Psicologia, 3(1), 81-94.

Ramdhony, D., Oogarah-Hanuman, V. e Somir, N. (2013). Career progression of women in accounting: the Case of Mauritius. International Journal of Humanities and Applied Sciences (IJHAS), 2(1), 22-28.

Risman, B. J. \& Johnson-Sumerford, D. (1998). Doing it fairly: a study of postgender marriages. Journal of Marriage and the Family, 60(1), 23-40.

Roberts, J. \& Coutts, J. (1992). Feminization and professionalization: a review of an emerging literature on the development of accounting in the United Kingdom. Accounting, Organizations and Society, 17, 379-395.

Sikka, P. \& Willmott, H. (1995). The power of "independence": defending and extending the jurisdiction of accounting in the United Kingdom. Accounting, Organisations and Society, 20(6), 547-581.

Schwartz, F. (1989). Management women and the new facts of life. Harvard Business Review, 65-76.

Scott, J. W. (1986). Gender: A useful category of historical analysis. The American Historical Review, 91(5), 1053-1101.

Walby, S. (1988). Gender segregation at work. Open University Press.

Whiting R. H. \& Wright, C. (2001). Explaining gender inequity in the New Zealand accounting profession. The British Accounting Review, 33(2), 191-222.

Windsor, C. \& Auyeung, P. (2006). The effect of gender and dependent children on professional accountants' career progression. Critical Perspectives on Accounting, 17, 828-844. 